\title{
The Paradoxical Effect of Paraquat on Leucyl-tRNA Levels in $E$. coli Provides New Insights for Amino Acid Therapy in Humans
}

\author{
Babu V. Bassa*, Olen R. Brown \\ John M. Dalton Cardiovascular Research Center, University of Missouri, Columbia, MO, USA \\ Email: ^bbassa9823@aol.com
}

How to cite this paper: Bassa, B.V. and Brown, O.R. (2018) The Paradoxical Effect of Paraquat on Leucyl-tRNA Levels in $E$. coli Provides New Insights for Amino Acid Therapy in Humans. CellBio, 7, 51-62. https://doi.org/10.4236/cellbio.2018.74005

Received: September 10, 2018

Accepted: October 17, 2018

Published: October 20, 2018

Copyright (c) 2018 by authors and Scientific Research Publishing Inc. This work is licensed under the Creative Commons Attribution International License (CC BY 4.0).

http://creativecommons.org/licenses/by/4.0/

(c) (i) Open Access

\begin{abstract}
Dihydroxyacid dehydratase (DHAD), the rate-limiting enzyme in the synthesis of branched-chain (BCA) amino acids in bacteria and plants, is sensitive to oxyradical toxicity. Oxidant stress reversibly inactivates DHAD and causes starvation for BCA and reversible cessation of growth in Escherichia coli [1] [2]. To better understand the underlying toxicity mechanisms, we have determined the cellular concentrations of charged-tRNAs for BCA, in E. coli treated with the redox-active chemical, paraquat. Contrary to expectation, in the paraquat-treated cells, the concentration of only charged leucyl-tRNA decreased dramatically; whereas, the concentrations of the other BCAs (valine and isoleucine) increased. This paradoxical result, the "paraquat effect" can be best explained if leucine is the most abundant amino acid in the $E$. coli proteins and therefore the rate-limiting building block in their synthesis. Based on this assumption, we investigated the concentration of free amino acids in E. coli and their relative abundances in E. coli proteins. Protein amino acid frequencies were determined by analyzing one-hundred gene bank protein sequences with software developed as described in Methods. Leucine is the most abundant amino acid in the E. coli proteins (10\%) and consequently, the cellular free leucine concentration is smaller and the native charged-leucyl-tRNA levels are much higher than those of valine and isoleucine. This has relevance to humans because: leucine-deprivation was shown to be beneficial in tumor suppression [3], and leucine-supplementation was beneficial in the recovery from exercise-induced muscle loss [4] [5], and leucine also occurs at a higher frequency in almost all human proteins. In three human protein categories, we examined it ranged from $9 \%$ to $17 \%$. This predominance of leucine in proteins would make cells vulnerable to impairment of the leucine pools and could explain our results in E. coli and some of the biological effects of free leucine in humans.
\end{abstract}




\section{Keywords}

E. coli, Leucine, Leucyl-tRNA, Paraquat, Leucine Abundance, Amino Acid Starvation, Cancer Therapy

\section{Introduction}

Exposure of E. coli $\mathrm{K}-12$ to the oxidative stress of aerobic paraquat, hyperbaric oxygen, or other oxidants, initiates a sequence of events leading to the induction of genetic stringency, a process discovered by Caschel [6] [7]. Stringency is known to result via starvation for amino acids. During classical stringency induction, amino acid pools are depleted and unloaded tRNAs are the "trigger" that induce ribosomes of stringent type cells (which contain the stringency protein) to synthesize guanosine tetra phosphate (ppGpp) [6] [8], which in turn binds to RNA polymerase [6] [8] and inhibits the synthesis of RNA. Oxidant stress inactivates the $[4 \mathrm{Fe}-4 \mathrm{~S}]$ cluster of $\mathrm{DHAD}(2)$ and thereby causes stringency, in minimal medium, by the deprivation of BCA. We demonstrated through our earlier work [9] [10] that paraquat causes oxidant stress similar to hyperbaric oxygen and other redox-cycling compounds and reversibly inactivates DHAD in $E$. coli $\mathrm{K}-12$. Paraquat toxicity in $E$. coli $\mathrm{K}-12$ is at least partly mediated, through its effects on DHAD, because supplementation of branched-chain amino acids mitigates the toxic effects of paraquat [10] via this mechanism.

\section{Methods}

\subsection{Bacterial Cultures and Treatments}

Escherichia coli K-12 (CGSC strain \#5073) from the E. coli Genetic Stock Center, Yale University School of Medicine, New Haven, Connecticut was used in all E. coli experiments. Cultures ( $110 \mathrm{ml}$ volume in $500 \mathrm{ml}$ flasks) were grown in a basal salts-glucose medium, supplemented with thiamin and niacin $(1 \mu \mathrm{g} / \mathrm{ml}$ each) [11]. One $\mathrm{ml}$ of paraquat $(110 \mathrm{mM})$ in sterile, distilled water was added to each exponentially-growing test cultures and the same volume of sterile, distilled water was added to control cultures. After addition of paraquat, cultures were shaken vigorously in a microbial incubator kept at $37^{\circ} \mathrm{C}(320 \mathrm{rpm}$, in a Lab Line Orbit Environ-Shaker, Lab line Instruments Inc., Melrose Parke, Illinois). The shaking continued to the indicated time periods in each case (Figure 1, and Figure 2). Growth of cultures before and after addition of paraquat was monitored by measuring of aseptically-removed aliquots using a Beckman spectrophotometer modified with Gilford electronics at an absorbance of $500 \mathrm{~nm}$ wavelength.

\subsection{DHAD Assay}

Dihydroxyacid dehydratase was assayed according to the method described in reference [9]. 


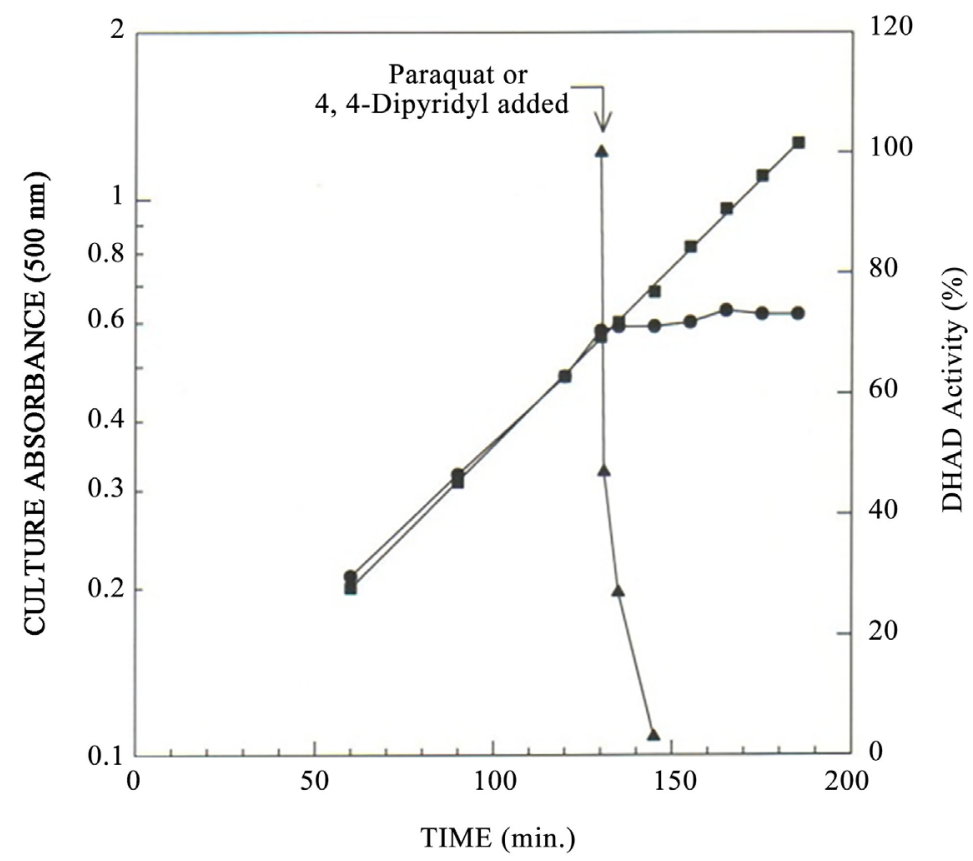

Figure 1. Inhibition of growth by paraquat in E. coli K-12 strain.

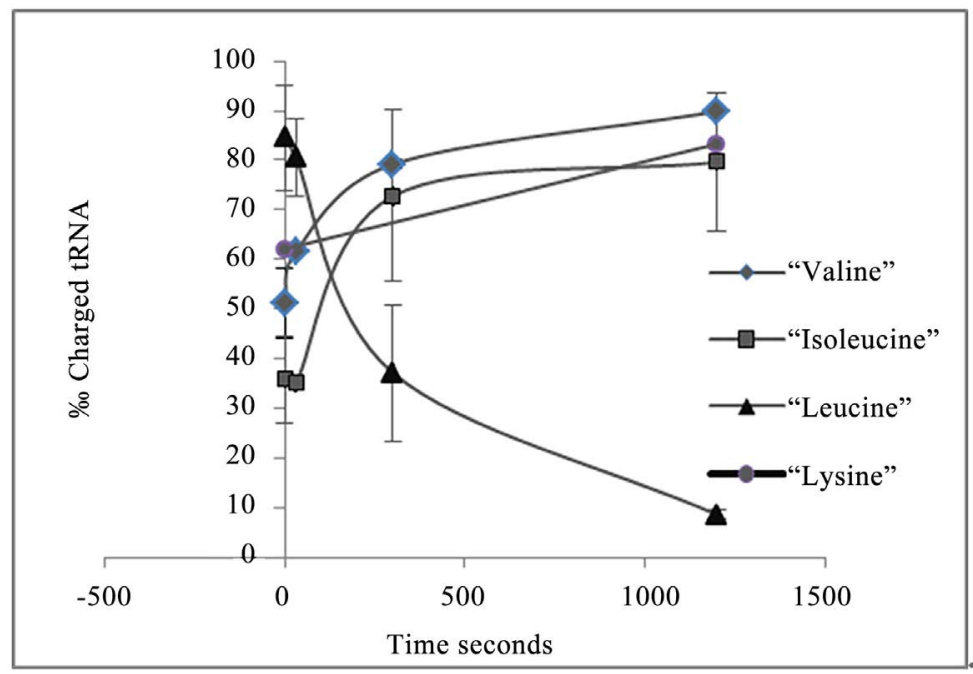

Figure 2. The paradoxical effect of paraquat (The Paraquat Effect) on amino acid charged tRNA levels in E. coli.

\subsection{Measurement of Cellular Free Amino Acids}

For the determination of amino acid pool sizes E. coli K-12 was grown on membranes as follows. A sterile Millipore membrane ( $47 \mathrm{~mm}, 0.45$ microns pore size) was placed on four sterile, absorbent Millipore pads that were pre-soaked with $7.5 \mathrm{ml}$ of sterile, MBS medium containing C-14 glucose at a final concentration of $0.55 \mathrm{M}, 1.58 \mathrm{mCi}$ per mmole. The membranes were first incubated at $37^{\circ} \mathrm{C}$ for $1 \mathrm{~h}$ and were then inoculated with the culture that was grown for at least 5 generations in minimal basal salt medium (MBS) containing C-14 glucose. The membranes thus prepared were incubated at $37^{\circ} \mathrm{C}$ for $2 \mathrm{~h}$ and then extracted 
with $3 \mathrm{ml}$ of $0.2 \mathrm{~N} \mathrm{HClO}_{4}$ and the extracts were centrifuged at $10,000 \mathrm{~g}$ for 10 min. The radioactivity in the pellets of this centrifugation step was measured. The supernatants were neutralized by the addition of $5 \%$ potassium carbonate. Five $\mathrm{ml}$ of a neutral solution from each sample was evaporated to dryness in a speed-vac concentrator. The dry residue containing free amino acids was derivatized with phenylisothiocyante (PITC) according to the method of Heinrikson et al. [12]. Briefly, the dry residue was reconstituted with $100 \mu$ of derivatization buffer (7:1:1:1, ethanol, water, triethylamine, and PITC), the mixture was sonified for five min and then kept at room temperature for $15 \mathrm{~min}$, following which the solution was evaporated to complete dryness in a speed-vac concentrator. A standard mixture of amino acids (Pierce Co., 25 nanomoles each) was added to MBS medium and derivatized with PITC by the same procedure as described immediately above. The PITC derivatives in the dry state were dissolved in $1 \mathrm{ml}$ of distilled water and analyzed by HPLC using the Waters PICO TAG amino acid system. Standard curves to measure the number of cells vs. radioactivity in the pellets were prepared with the culture remaining after inoculation of the membranes. We reported the free amino acid pool sizes of the 12 amino acids that could be assessed reliably and not the remaining eight which were uncertain because of their comparatively low concentrations.

\subsection{Determination of Percentages of Loaded-tRNAs}

E. coli was grown in the MBS medium supplemented with niacin and thiamin. For this $110 \mathrm{ml}$ of sterile medium was inoculated with overnight cultures. When the cultures reached exponential growth $(0.7-0.9$ absorbance at $500 \mathrm{~nm}), 1 \mathrm{ml}$ of $110 \mathrm{mM}$ paraquat was added and the cultures were subjected to shaking at 320 rpm for $0.5,1.0,5.0$, or $20.0 \mathrm{~min}$ in different experimental schedules. A $12.5 \mathrm{ml}$ solution of $55 \%$ TCA, and $1.25 \mathrm{ml}$ of $1 \%$ SDS were added in succession to the cultures with a 1-min shaking period in between these two additions. The mixture was then transferred to a previously chilled $250 \mathrm{ml}$ centrifuge bottles and subjected to centrifugation at 10,000 $\mathrm{g}$ for $10 \mathrm{~min}$. The supernatant was discarded and the pellet was extracted for RNA with TRI reagent (Molecular Research Center Inc, Cincinnati, $\mathrm{OH}$ ) according to the protocol provided with the reagent. Briefly, the cell pellet was suspended in $2.5 \mathrm{ml}$ of the TRI reagent. After mixing vigorously, $0.5 \mathrm{ml}$ of chloroform was added and after further mixing the suspension was centrifuged at 13,000 $\mathrm{g}$ for $10 \mathrm{~min}$. the upper aqueous phase was separated and RNA was precipitated by the addition of $1.25 \mathrm{ml}$ of is opropanol. After cooling at $4^{\circ} \mathrm{C}$ the RNA was separated by centrifugation at $13,500 \mathrm{~g}$ for 10 min. The RNA pellet was washed with $2.5 \mathrm{ml}$ of $75 \%$ ethanol. Determination of the charged levels of tRNA (percent loaded tRNA) involved two major steps namely; periodate oxidation and the amino acid acceptance assay (Folk and Berg, 1970) [13].

Periodate oxidation. After the RNA wash, the pellet was dissolved in $620 \mu \mathrm{l}$ of $0.25 \mathrm{M}$ sodium acetate buffer $\mathrm{pH}$ 5.0, containing 0.5\% SDS and 1mM EDTA. 
Aliquots of $270 \mu \mathrm{l}$ of this solution were drawn into two different tubes. Then 30 $\mu \mathrm{l}$ of the SDS buffer was added to one tube and $30 \mu \mathrm{l}$ of $12.5 \%$ periodate made in the same buffer was added to the second tube. Both the tubes were incubated at $25^{\circ} \mathrm{C}$ for $30 \mathrm{~min}$ and $27 \mu \mathrm{l}$ of $3 \mathrm{M}$ sodium acetate, $\mathrm{pH} 5.2$ and $720 \mu \mathrm{l}$ of ice-chilled ethanol were added to both tubes. The RNA pellet was then separated by centrifugation and incubated for $10 \mathrm{~min}$ in the dark with $0.1 \mathrm{M}$ acetate buffer, pH 4.6 containing $0.1 \mathrm{M}$ ethylene glycol, in order to destroy excess periodate. The RNA from this mixture was separated as before. The ideal concentration of periodate was determined by experiments using deacylated (stripped) tRNA.

Amino acid acceptance assay. Amino acid acceptance assays were performed according to the method of Yang and Novelli [14], slightly modified as described below. The RNA pellet obtained in the previous step was dissolved in $225 \mu$ of the assay buffer. The assay buffer contained 90 micro moles of Tris $\mathrm{HCl}(\mathrm{pH}$ 7.5), 0.8 micro mole ATP, $2.4 \mu \mathrm{mol}$ magnesium acetate, $10 \mu$ mole $\mathrm{KCl}, 4 \mathrm{nmol}$ each of the other amino acids and $3.8 \mathrm{nmol}$ of the labeled $\left(\mathrm{U}-{ }^{14} \mathrm{C}\right)$ amino acid, and 165 units of the aminoacyl- tRNA synthetase (E. coli enzyme mixture, Sigma Chemical Co.). The reaction was terminated by adding $50 \mu \mathrm{lof} 4 \mathrm{mg} / \mathrm{ml} \mathrm{BSA}$ and $950 \mu \mathrm{l}$ of $10 \%$ TCA. The precipitate was separated by centrifugation and was washed two times with $950 \mu \mathrm{l}$ volumes of 10\% TCA. Finally, the pellet was suspended in $500 \mu \mathrm{l}$ of $2.5 \% \mathrm{TCA}$. The suspension was transferred to scintillation fluid. The tube was washed with $500 \mu \mathrm{l}$ of water. The washings were also transferred to the scintillation fluid for counting the radioactivity. The percentage of the loaded tRNA was determined from the count rate (CPM) obtained for the periodate-treated sample divided by the CPM obtained for the buffer treated sample.

\subsection{Determination of Relative Abundance of Amino Acids in E. coli Proteins}

For the analysis of the frequency of amino acids in the E. coli K12 proteins, one-hundred E. coli K12 protein sequences were obtained from the gene bank [15]. To assure randomness, the first 100 proteins appearing under the search criteria of " $E$. coli K-12" were chosen for the analysis after excluding predicted and hypothetical sequences. The analysis was carried out with "Composition-20" a software program developed by one of us (Bassa $\mathrm{V}$ Babu). This program counts the number of occurrences of each amino acid in the query sequence and calculates its percentage representation. The output includes number of times and percentage of occurrence of each amino acid in the total length of the query sequence. Since the protein sequences in these NCBI deposits are translated from the corresponding cDNA sequences, the actual count represents the codons corresponding to various amino acids. The program does analysis on the sequence provided to it directly (by copying and pasting). The program is not a search engine and is not connected to the databases or the internet. The program saves all the queries and output in a local database attached to it. A limited number of copies of the program will be provided to the reviewers and the readers free of 
cost for academic use.

\subsection{Statistics}

Experiments on the charged levels of tRNAs were done with triplicate samples and repeated at least twice for each of the four amino acids. The values were pooled for statistical analysis. For the amino acid pool sizes a typical experiment with six replicates is presented. Protein abundances were determined with our software on E. coli proteins $(n=100)$, human cytoplasmic proteins $(n=47)$, and human leucine-repeat-containing proteins $(\mathrm{n}=47)$ and mitochondrial proteins $(\mathrm{n}=13)$. These sequences were obtained from the NCBI protein database. To ensure randomness, the specified numbers of sequences, appearing first in the database were taken for analysis. We excluded hypothetical and predicted sequences from this sampling. All the differences were tested for significance with a two tailed student t-test as specified in the legends.

\section{Results and Discussion}

In the present project we have directly demonstrated the effect of paraquat on the cellular content of charged branched- chain amino acid tRNAs in the E. coli K-12 strain. Aerobic paraquat treatment stops growth that is prevented by the presence of amino acids in the culture medium (Figure 1). We anticipated that this would be accompanied by depletion of the percentage of charged valyl-, isoleucyl-, and leucyl-tRNAs in the cell. Contrary to this expectation, paraquat treatment caused a dramatic elevation of charged valyl- and isoleucyl-tRNAs. The charged lysyl-tRNA, which was not expected to change, also increased similarly (Figure 2). However, the percentage of leucine charged-tRNA, which is higher than that of the other three under native conditions, decreased markedly to about $10 \%$ (Figure 2) and this preceded the depression of growth which began within seconds. These unexpected results prompted us to investigate the cellular distribution of leucine between the free pool, tRNA, and proteins. Under native conditions, on average, the free pool size of leucine is much smaller than that of many other amino acids (Table 1). The leucine to valine ratio is about 0.06 and the leucine to isoleucine ratio is about 0.12 . The correlation between the cellular free amino acid pool sizes and the amino acid frequencies in the proteins is very weak $(r=0.09)$. However, there is a clear positive correlation between native charged levels of tRNAs corresponding to BCA and the abundance of BCA in the cellular proteins $(r=0.99)$ with highly significant differences between their charged levels $(\mathrm{p}<0.001)$. To determine the abundance of amino acids in proteins, one-hundred randomly selected $E$. coli K-12 protein sequences obtained from the gene bank were analyzed for their amino acid compositions by the software program named "Composition-20" which we developed for this purpose (see methods). The program analyzes the sequences provided to it by copying and pasting. The sequences analyzed here are obtained from the NCBI protein database [15]. These NCBI reference sequences, meaning each sequence 
Table 1. Amino acid pools ( $\mu$ moles/g.dry.wt) and leucine pool ratios with that of the other amino acids in $E$. coli $(\mathrm{K}-12)$.

\begin{tabular}{ccc}
\hline Name & Quantity & Leu. ratio \\
\hline Leu & $0.19 \pm 0.02$ & \\
Phe & $0.2 \pm 0.03$ & 0.95 \\
Tyr & $0.27 \pm 0.03$ & 0.70 \\
His & $0.35 \pm 0.06$ & 0.54 \\
Arg & $0.84 \pm 0.37$ & 0.23 \\
Asn & $0.99 \pm 0.18$ & 0.19 \\
Pro & $1.11 \pm 0.05$ & 0.17 \\
Ser & $1.41 \pm 0.32$ & 0.13 \\
Lys & $1.50 \pm 0.25$ & 0.13 \\
Ile & $1.53 \pm 0.25$ & 0.12 \\
Trp & $1.91 \pm 0.43$ & 0.01 \\
Val & $2.94 \pm 0.46$ & 0.06 \\
\hline
\end{tabular}

is representative of one protein belonging to one species. Since this gene bank protein sequence deposits are originally translated from cDNAs, the results of this analysis actually reflects the number of codons present in the respective mRNAs for each of the 20 amino acids. The method is therefore well suited for understanding the consequences of amino acid deprivation inside the cell. Each protein sequence chosen was at least 500 amino acids in length. The gene bank contained large number of predicted and hypothetical sequence deposits, which we excluded from this study. The total amino acid length of these concatenated sequences is 69,685 , which is comprised of $10 \%$ leucine. This is followed by alanine at $9 \%$ (Table 1). Cysteine is the least abundant amino acid at $0.9 \%$. In $E$. coli leucine synthesis requires three additional enzymatic reactions compared to the synthesis of valine and isoleucine [16]. The cellular free leucine concentration is therefore a reflection of lengthy biosynthetic procedure and leucine's rapid incorporation into proteins. As shown in Table 1 the leucine free pool is the smallest of the 12 amino acids reported here. It is about 15 times smaller than the valine free pool in the cell.

Under conditions of oxidative stress and resultant BCA starvation, two factors potentially could contribute to the cessation of growth in $E$. coli $K-12$. The first factor is the induction of stringency. However, the stringent response in $E$. coli $K-12$ is still poorly understood [17]. Our finding that paraquat causes the accumulation of only leucyl-unloaded tRNAs is noteworthy and needs an explanation. The second factor is the appearance of leucine at the highest frequency in the cellular proteins. This lopsided distribution of leucine is likely to make the free leucine pool size the weakest link in the survival of the cell. Mere non-availability of leucine can disrupt protein synthesis. As discussed later, this 
is the basic idea behind employing amino acid starvation in the treatment of cancer in humans, where the actively dividing cancer cells have a special requirement for specific amino acids [18]. Our data show that paraquat causes a rapid accumulation of charged-amino acid tRNAs for valine and isoleucine but causes a very rapid decrease in the concentration of charged-leucyl-tRNA. These data indicate that inside the $E$. coli cells amino acid starvation will not go beyond the starvation for leucine, all due to an uneven distribution of amino acids across the E. coli protein sequences. More recently, employing ppGpp deficient strains of $E$. coli, it has been shown that ppGpp is solely responsible for inhibition of growth in E. coli [17]. The explanation to the paraquat effect is extremely complicated in E. coli because not only leucine is more abundant in the proteins, but also leucine is represented by six different codons in the corresponding mRNA and therefore six different tRNAs. The implication is that under all conditions of amino acid deprivation, that include leucine deprivation, unloaded leucyl tRNAs will be the first to trigger the ppGpp synthesis. Our results are more readily explained by our new data on: the amino acid pool sizes, the concentrations of the native charged tRNAs for these amino acids, and the amino acid composition of the E. coli proteins. Relatively higher concentrations of charged leucyl-tRNAs under native conditions indicate that leucine is rapidly channeled into the proteins thus creating a delicate, naturally selected equilibrium of the free leucine pool in the cell.

Humans are incapable of synthesizing BCAs and they have no stringent response. Any inhibition of cellular growth under amino acid starvation has to be due to a disruption of protein chain assembly. There has been continuing and recently renewed interest in the role of branched-chain-amino acids, especially leucine, in two major areas of research. These interests are: amino acid deprivation in cancer therapy, and branched amino acid (BCA) supplementation in the treatment of exercise- related muscle loss. For cancer, research has focused on amino acid deprivation of: glycine, proline, asparagine, glutamine, and leucine (the latter is significant to this report) with some positive results [18] [19] [20] [21]. Research on the mechanism of exercise-related muscle loss and its therapy, has found that leucine is outstanding among the BCAs in restoring muscle protein synthesis [4]. Although several mechanisms have been proposed to explain the role of leucine in both the above mentioned cases, the predominance of leucine in human proteins has never been considered to account for this. In this study we have analyzed three categories of human proteins using our software. They are cytoplasmic proteins that do not contain leucine-rich repeats (combined length $=39,350$ amino acids); proteins containing leucine-rich repeats (combined length $=43,412$ ); and mitochondrial proteins (from five different mitochondrial genomes). We have decided on these three categories based on our initial screening of the human proteins for leucine frequency. As shown in Table 1, the leucine frequency in these three categories is $9 \%, 15 \%$, and $17 \%$ on the average, respectively, and $6.6 \%$ in elastin where alanine, glycine, proline and 
valine are the predominant amino acids (Table 2). Elastin is a recent target for glycine deprivation which is being promoted by some private parties [22], because elastin is required for angiogenesis in the fast growing tumors. It can be concluded that most of the cellular leucine in humans and in $E$. coli is situated in the protein sequences. On the average, leucine is even more abundant in human proteins than in the E. coli proteins. The predominance of leucine in proteins in general and mitochondrial proteins in particular explains, at least partially, the positive effects of leucine supplementation in the recovery from muscle loss. In both $E$. coli $\mathrm{K}-12$ and in human tissues, the high demand for leucine as a constituent of proteins would result in smaller cellular free leucine pools that can be depleted rapidly by nutritional starvation in actively dividing cells. Additionally, leucine is an essential amino acid in humans and its deprivation as a strategy has many advantages. We expect that our findings will stimulate research on the amino acid pool sizes, and charged tRNA levels in various human cell types. The "Paraquat effect "that we have described here is important information which can help understand better, the physiological properties of leucine in humans.

Table 2. The amino acid frequencies in E. coli and human proteins.

\begin{tabular}{|c|c|c|c|c|c|}
\hline Name & E. Coli & Cyto. H & LRC. H & Mito. H & Elastin. $\mathrm{H}^{\star}$ \\
\hline Ala & $9.2 \pm 2.1$ & $6.6 \pm 2.1$ & $6.6 \pm 2.2$ & 6.8 & 21.8 \\
\hline Cys & $0.9 \pm 0.6$ & $2.3 \pm 1.6$ & $2.6 \pm 1.2$ & 0.6 & 0.3 \\
\hline Asp & $5.8 \pm 1.4$ & $4.9 \pm 1.0$ & $4.3 \pm 0.9$ & 1.7 & 0.3 \\
\hline Glu & $6.3 \pm 1.8$ & $7.1 \pm 2.3$ & $6.0 \pm 2.1$ & 2.3 & 0.5 \\
\hline Phe & $3.8 \pm 1.3$ & $3.7 \pm 1.4$ & $3.4 \pm 1.1$ & 5.7 & 2.2 \\
\hline Gly & $7.6 \pm 1.5$ & $6.3 \pm 1.8$ & $6.1 \pm 1.8$ & 5.6 & 28.6 \\
\hline His & $2.3 \pm 0.9$ & $2.4 \pm 1.1$ & $2.8 \pm 0.6$ & 2.6 & 0.2 \\
\hline Ile & $5.5 \pm 1.6$ & $4.9 \pm 1.6$ & $4.0 \pm 1.7$ & 8.4 & 2.3 \\
\hline Lys & $4.5 \pm 1.3$ & $5.9 \pm 2.2$ & $3.9 \pm 2.0$ & 2.5 & 4.7 \\
\hline Leu & $10 \pm 2.0$ & $9.6 \pm 2.1$ & $15.9 \pm 3.5$ & 17 & 6.5 \\
\hline Met & $2.6 \pm 0.8$ & $2.1 \pm 0.9$ & $1.7 \pm 0.7$ & 5.5 & 0.1 \\
\hline Asn & $4.3 \pm 1.3$ & $4.0 \pm 1.5$ & $5.5 \pm 1.9$ & 4.3 & 0 \\
\hline Pro & $4.5 \pm 1.1$ & $5.8 \pm 2.1$ & $6.0 \pm 2.0$ & 5.8 & 12.5 \\
\hline Gln & $4.7 \pm 1.3$ & $4.4 \pm 1.6$ & $4.6 \pm 1.4$ & 2.4 & 1.1 \\
\hline Arg & $5.7 \pm 1.7$ & $4.7 \pm 1.5$ & $5.5 \pm 1.7$ & 1.7 & 1.4 \\
\hline Ser & $5.6 \pm 1.2$ & $8.1 \pm 2.5$ & $8.3 \pm 1.5$ & 7.3 & 1.6 \\
\hline Thr & $5.4 \pm 1.2$ & $5.4 \pm 1.1$ & $4.9 \pm 1.2$ & 9.2 & 1.4 \\
\hline Val & $6.7 \pm 1.4$ & $6.0 \pm 1.3$ & $4.9 \pm 1.0$ & 4.4 & 12.5 \\
\hline $\operatorname{Trp}$ & $1.6 \pm 1.1$ & $1.1 \pm 0.6$ & $1.0 \pm 0.5$ & 2.7 & 0 \\
\hline Tyr & $3.2 \pm 1.3$ & $2.5 \pm 1.0$ & $1.9 \pm 0.8$ & 3.6 & 2 \\
\hline
\end{tabular}


Effects of paraquat and 4,4-dipyridyl (the inactive analogue of paraquat) at final concentrations of $1 \mathrm{mM}$ on growth and DHAD specific activity in $E$. coli $\mathrm{K}-12$ incubated with aeration at $37^{\circ} \mathrm{C}$ in MBS medium plus niacin and thymine with no amino acids. Cultural absorbance (on an exponential scale as a measure of growth) and DHAD specific activity (an enzymatic site of known toxicity by aerobic paraquat) are shown before and after addition of paraquat and its redox-inactive analogue. Cultural growth (solid and open circles) and DHAD specific activity (solid triangles) are shown vs. time in min. Values represent means of triplicate samples.

Effects of paraquat on the charged to free ratios of tRNAs for the 3 branched-chain amino acids (Valine, Isoleucine, Leucine) and Lysine (as a control). Exponentially growing E. coli $\mathrm{K}-12$ cultures were treated with paraquat a final concentration of $1 \mathrm{mM}$, and cultures were extracted for RNA. Acceptances of C-14 labeled amino acids (valine, leucine, or isoleucine) by periodate-treated and untreated RNA samples (representing about $3 \times 10^{10}$ cells in each case) in the presence of a commercial preparation of aminoacy-tRNA-synthetase were determined. The charged-level in each case was calculated as the percentage incorporation of radioactivity into periodate-treated RNA samples, compared to that of the untreated RNA samples. The earliest sampling after time zero (when paraquat was added) was $30 \mathrm{sec}(\mathrm{n}=6)$.

Student t-Test was applied for the following differences: Charged levels of tRNAs for Valine vs leucine $(\mathrm{p}<0.0001)$, Valine vs Isoleucine $(\mathrm{p}<0.001)$, Valine time zero vs Valine $5 \mathrm{~min}$ (0.0001), Leucine time zero vs leucine $5 \mathrm{~min}$ ( $\mathrm{p}<$ $0.0001)$, Isoleucine time zero vs Isoleucine $5 \mathrm{~min}(\mathrm{p}<0.0001)$.

The cellular concentration of free amino acids was determined as described in the "Methods". The technique involved radio-labeling of the cells with C- 14 glucose, and PITC derivatization of the amino acids followed by HPLC ( $n=6$ per each data point). In view of difficulties in capturing the free amino acid concentrations only 12 amino acid pool sizes are reported here. The student test was applied for the differences between Valine vs leucine $(\mathrm{p}<0.0001)$ and Isoleucine vs leucine $(\mathrm{p}<0.0001)$ pool sizes.

E. coli $(\mathrm{K}-12)$ and human protein sequences were obtained from the NCBI protein database. E. coli protein sequences $(n=100)$ randomly selected were analyzed for their amino acid composition by a software program developed by the authors (see methods). The concatenated sequence length is 69,685 for $E$. coli proteins, 39,350 for human cytoplasmic proteins, and 42,796 for human leucine-repeats-containing (LRC) proteins. Amino acid composition of proteins from a representative mitochondrial genome (13 proteins in total) is presented here. For elastin (required for angiogenesis in the tumors and therefore a target of glycine deprivation), two deposits available in the gene bank are combined and the percentage of each of the 20 amino acids in the concatenated sequence is presented here. Student t-test was applied on the following amino acid frequencies: Alanine vs Leucine for E. coli proteins ( $\mathrm{p}<0.0001)$; Alanine vs leucine for each of the three categories of human proteins; and for the leucine content of 
cytoplasmic vs leucine-repeat-containing proteins $(\mathrm{p}<0.0001)$ and the leucine content of cytoplasmic vs mitochondrial proteins $(\mathrm{p}<0.0001)$.

\section{Conclusions}

Based on our findings described here, we propose that higher basal levels of charged leucyl-tRNA are the consequence of higher abundance of leucine in the proteins and together they have resulted in the smaller free pools of leucine ultimately causing the paraquat effect in $E$. coli. This observation is of paramount importance to humans, because the analysis of protein sequences available in the gene bank shows (Table 2) that leucine is the most abundant amino acid also in the human proteins, especially the mitochondrial proteins. Our data for the first time systematically document this information. The software program used here provides a simple way to analyze hundreds of protein sequences available in the gene bank and will be useful in future applications. Our results stress on the importance of determining the cellular free amino acid pool sizes before deciding on a target amino acid in the amino acid starvation based cancer therapies. In the light of our findings, we believe that leucine is a better candidate for the starvation of metastatic cells, and therefore leucine must be explored more thoroughly in this regard.

\section{Conflicts of Interest}

The authors declare no conflicts of interest regarding the publication of this paper.

\section{References}

[1] Brown, O.R. and Yein, F. (1978) Dihydroxyacid Dehydratase: The Site of Hyperbaric Oxygen Poisoning in Branched-Chain Amino Acid Biosynthesis. Biochemical and Biophysical Research Communications, 85, 1219-1224.

[2] Flint, D.H., Smyk-Randall, E., Turminello, J.F., Draczynska-Lusiak, B. and Brown, O.R. (1993) The Inactivation of Dihydroxy-Acid Dehydratase in Escherichia coli Treated with Hyperbaric Oxygen Occurs Because of the Destruction of Its Fe-S Cluster, But the Enzyme Remains in the Cell in a Form that Can Be Reactivated. The Journal of Biological Chemistry, 268, 25547-25552.

[3] Xiao, F., et al. (2016) Leucine Deprivation Inhibits Proliferation and Induces Apoptosis of Human Breast Cancer Cells via Fatty Acid Synthase. Oncotarget, 27, 63679-63689. https://doi.org/10.18632/oncotarget.11626

[4] Phillips, S.M. (2016) The Impact of Protein Quality on the Promotion of Resistance Exercise-Induced Changes in Muscle Mass. Nutrition \& Metabolism (London) 13, 64. https://doi.org/10.1186/s12986-016-0124-8

[5] Wolfe, R.R. (2017) Branched-Chain Amino Acids and Muscle Protein Synthesis in Humans: Myth or Reality? Journal of the International Society of Sports Nutrition, 14, 30. https://doi.org/10.1186/s12970-017-0184-9

[6] Cashel, M. (1969) The Control of Ribonucleic acid Synthesis in Escherichia coli. IV. Relevance of Phosphorylated Compounds from Amino Acid Starved Stringent Strains. The Journal of Biological Chemistry, 244, 3133-3141.

[7] Liu, K., Bittner, A.N. and Wang, J.D. (2015) Diversity in (p) ppGpp Metabolism and 
Effector. Current Opinion in Microbiology, 24, 72-79.

https://doi.org/10.1016/j.mib.2015.01.012

[8] Syal, K. and Chatterji, D. (2015) Differential Binding of ppGpp and pppGpp to $E$. coli RNA Polymerase: Photo-Labeling and Mass Spectral Studies. Genes Cells, 12, 1006-1016. https://doi.org/10.1111/gtc.12304

[9] Babu, B.N. and Brown, O.R. (1995) Quantitative Effects of Redox-Cycling Chemicals on the Oxidant Sensitive Enzyme Dihydroxy-Aciddehydratase. Microbios, 82, 157-170.

[10] Seither, R.L. and Brown, O.R. (1984) Paraquat and Nitrofurantoin Inhibit Growth of Escherichia coli by Inducing Stringency. Journal of Toxicology and Environmental Health, 14, 763-771. https://doi.org/10.1080/15287398409530625

[11] Boehme, D.E., Vincent, K. and Brown, O.R. (1976) Oxygen Toxicity and Inhibition of Amino Acid Biosynthesis. Nature, 262, 418-420. https://doi.org/10.1038/262418a0

[12] Heinrikson, R.L. and Meredith, S.C. (1984) Amino Acid Analysis by Reverse-Phase High Performance Liquid Chromatography: Precolumn Derivatization with Phenylisothiocyanate. Analytical Biochemistry, 136, 65-74. https://doi.org/10.1016/0003-2697(84)90307-5

[13] Folk, W.R. and Berg, P. (1970) Characterization of Altered Forms of Glycyl Transfer Ribonucleic Acid Synthetase and Effects of Such Alterations on Aminoacyl Transfer Ribonucleic Acid Synthesis in Vivo. Journal of Bacteriology, 102, 204-212.

[14] Yang, W., David, G. and Novelli, G.D. (1971) Analysis of Isoaccepting tRNAs in Mammalian Tissues and Cells. Methods in Enzymology, 20, 44-55. https://doi.org/10.1016/S0076-6879(71)20007-0

[15] E. coli \& Human Cytoplasmic Proteins. https://www.ncbi.nlm.nih.gov/protein \& Human Mitochondrial Proteins.

https://www.ncbi.nlm.nih.gov/nuccore/?term=mitochondrion+genome+complete+ $\underline{\text { homo+sapiens }}$

[16] Amorim Franco, T.M. and Blanchard, J.S. (2017) Bacterial Branched-Chain Amino Acid Biosynthesis: Structures, Mechanisms, and Drugability. Biochemistry, 56, 5849-5865. https://doi.org/10.1021/acs.biochem.7b00849

[17] Katarzyna, P., Helen, M., Nadège, P. and Michael, C. (2011) ppGpp Is the Major Source of Growth Rate Control in E. coli. Environmental Microbiology, 13, 563-575. https://doi.org/10.1111/j.1462-2920.2010.02357.x

[18] Maddocks, O.D.K., Athineos, D., Cheung, E.C., Lee, P., Zhang, T., van den Broek, N.J.F., Mackay, G.M., Labuschagne, C.F., Gay, D., Kruiswijk, F., Blagih, J., Vincent, D.F., Campbell, K.J., Ceteci, F., Sansom, O.J., Blyth, K. and Vousden, K.H. (2017) Modulating the Therapeutic Response of Tumours to Dietary Serine and Glycine Starvation. Nature, 19, 372-376. https://doi.org/10.1038/nature22056

[19] Fung, M.K.L. and Chan, G.C. (2017) Drug-Induced Amino Acid Deprivation as Strategy for Cancer Therapy. Journal of Hematology \& Oncology, 10, 144. https://doi.org/10.1186/s13045-017-0509-9

[20] Loayza-Puch, F., et al. (2016) Tumour-Specific Proline Vulnerability Uncovered by Differential Ribosome Codon Reading. Nature, 25, 490-494. https://doi.org/10.1038/nature16982

[21] Sullivan, M.R. and Vander Heiden, M.G. (2017) When Cancer Needs What's Non-Essential. Nature Cell Biology, 19, 418-420. https://doi.org/10.1038/ncb3523

[22] http://aminoacidstudies.org/cancer/ 